\title{
Carbon Cultures: Technology Planning for Energy and Climate in the US and EU
}

\author{
Mads Dahl Gjefsen
}

Emerging technologies are not simply pursued out of economic interests, but also on the basis of assumptions about the societies and publics that technologies will serve. This paper compares how carbon dioxide capture and storage - a technology for sustainable energy generation - has been supported in the United States and European Union over the last decade. Distinct land ownership laws and market structures have helped legitimate different groups of actors as stakeholders in the technology, and $\mathrm{CO} 2$ has been redefined in relation to different policy narratives and legal ontologies in the two sites. Climate change mitigation might appear to depend on international cooperation founded on a shared epistemic basis. However, this article suggests that mitigation options should not simply be assessed as functions of technical qualities, but also be understood in relation to how political actors articulate and pursue the societal implications of technological futures.

Keywords: Climate change, comparative policy, co-production

\section{Introduction}

Carbon dioxide capture and storage (CCS) is a set of technologies aimed at capturing $\mathrm{CO} 2$ emitted from large stationary sources, such as power plants burning fossil fuels, and transporting it for safe, permanent storage in geological formations. The concept of CO2 storage is rooted in 1970s "enhanced oil recovery" where CO2 was injected into oil fields to manipulate pressure - still widely practiced in the US. CCS could curb emissions from power plants running on coal, which is the world's largest source of energy and also one of the largest anthropogenic sources of $\mathrm{CO} 2$ emissions. CCS figures prominently in overviews of the technologies that are needed in order to meet the international target of limiting the global temperature increase to $2{ }^{\circ} \mathrm{C}$ above pre-industrial levels (Pacala \& Socolow, 2004; IPCC, 2005; MIT, 2007; Stern, 2007 IEA, 2009). The technology has seen a dramatic increase in political attention and support in many countries over the last decade, motivated in part by efforts to jointly address climate change and energy demands (Langhelle \& Meadowcroft, 2009; Markusson et al., 2012). Political enthusiasm aside, however, environmental organizations have been divided on questions about the safety and desirability of CCS (Anderson \& Chiavari, 2009), and CCS developers have voiced concerns about a slow speed of actual progress (Shackley \& Evar, 2012). The challenges are many 
and varied. Obstacles and uncertainties are said to include issues of cost, policy and regulation, technology development and public support (Markusson et al., 2011; Nykvist, 2013; Stigson et al., 2012). Distinct barriers are frequently listed in technology assessments by government and industry actors, calling for climate change legislation (such as the Norwegian tax on offshore CO2 emissions which in 1996 motivated oil company Statoil to begin separating CO2 from natural gas and inject it below the seabed), and voicing concerns that "[p]ublic understanding of CCS remains low" (the apparent assumption being that increased understanding would strengthen public support for the technology) (Global CCS Institute, 2012: 2-3).

The prevalence of compartmentalized "obstacles" and "barriers", both within academic literature on CCS and amongst developers of the technology, can be usefully supplemented by Science and Technology Studies (STS) approaches to the integrated study of narratives, materialities and institutional practices around technological development (for notable examples, see Markusson et al., 2012; Narita, 2010; Pollak et al., 2011). STS interpretations might shed light on how some concerns about CCS come to be more relevant in certain contexts rather than others, and, conversely, how different actors articulate the "purpose" of CCS and render it meaningful as worthy of pursuit. Stigson and colleagues argue that evaluating the relative importance of different "obstacles" to CCS in different contexts could have important policy implications (Stigson et al., 2012: 615). But understanding how CCS is presented (and contested) as a political object could give theoretical insights as well. Questioning claims about its inherent meanings might not only improve our understanding of the relationships between societal and technological change, but could also help us ask productive questions about how climate change and other seemingly global concerns are formulated as grounds for action in different contexts.

Here I ask what has characterized the engagement with CCS in the United States (US) and the European Union (EU), two political contexts where the technology has gained particular prominence over the previous decade. The paper is explorative and takes a comparative approach in order to examine how ideas about CCS have become established in relation to legal, institutional and other societal factors, rather than as direct functions of predefined technological characteristics. I do not aim to assess the technical performance of CCS or make judgements about its relative success, but concentrate instead on identifying how CCS has become associated with broader societal trends and political pursuits, subjected to different regulatory traditions, and gained significance to different groups of stakeholders.

In what follows, I describe my theoretical and methodological approach and position the paper in relation to existing literature on the political and social dimensions of CCS. I then go on to outline and compare the societal and political ambitions CCS has increasingly become associated with in the US and EU. I argue that the technology has become enrolled in distinct forms of federalism, helping the US launch technology-focused international climate change mitigation efforts as an alternative to imposing domestic emissions regulation on the one hand, and underwriting a project of European integration, partly through the institutionalization of stakeholder participation and the design of funding schemes on the other. I argue that comparison helps identify differences with important implications for the crossnational sharing of expertise and learning that CCS developers themselves present as 
a key factor for the future of the technology (Global CCS Institute, 2012: 3), and that theoretical resources from STS can help unpack the ways in which assumedly unified global concerns are addressed by political actors.

\section{Literature and Methods}

This article seeks to complement two largely distinct strands of research on the social and political dimensions of CCS. The first strand deals with the measurement of political support for CCS, and is represented largely by cross-national comparative research (Bäckstrand et al., 2011; de Coninck \& Bäckstrand, 2011; Meadowcroft \& Langhelle, 2009; Tjernshaugen, 2008). As Shackley (2012) points out, this literature often explains political support for CCS with reference to the "interest model" of politics, where economic rationality suggests that national governments would seek to maintain cheap and abundant fossil fuel energy supplies in a carbon constrained future. This model might explain the more recent stagnation of CCS efforts with reference to factors such as the continued high costs of the technology, and the emergence of alternative energy production strategies based on less $\mathrm{CO} 2$ intensive energy production, such as that currently witnessed in what reporters refers to as the "shale gas revolution" of the United States (The Economist, 2012). While useful for explaining why political entities initiate or suspend support for CCS, such research rarely seeks to unpack how promotion or opposition to the technology takes shape within different contexts.

A second strand of research consists of a diverse body of literature on public perception and engagement with CCS. It includes single case studies (Feenstra et al., 2010), risk-perception studies (Singleton et al., 2009), and comparative studies of public awareness and attitudes (Ashworth et al., 2012; Huijts et al., 2007; Oltra et al., 2010; Upham \& Roberts, 2011). These perception-oriented approaches have delivered rich accounts of a broad range of public responses both to individual CCS projects and to more abstract notions of the desirability of CCS as a climate change mitigation strategy. They tell us, for instance, that publics are generally less aware of CCS than they are of renewable energy technologies, and that concerns about CCS include fears of $\mathrm{CO} 2$ leaking from reservoirs or that $\mathrm{CO} 2$ will explode, concerns about local projects negatively affecting property values, or that CCS diverts funding away from renewable energy. However, these approaches have not generally sought to connect their observations with trends in political narratives and support-structures.

These two strands of research can be usefully supplemented by STS approaches to technological change as something that both enables and remakes constellations of agency and possibility, and which cuts across boundaries between the technical, social and political (Bijker et al., 1987; Winner, 1988; Wynne, 1988). Placed at the interface between politically charged concerns about energy security and environmental protection, and planned according to prediction-based epistemologies about technological development and profitability trajectories, CCS is not simply adapted to national needs and interests in a straightforward manner. Instead, the envisaged ability of CCS to address issues of nature management is intimately linked with negotiations about which social and political aims should be pursued in the first place, by which means, and to whose benefit. Thus, the making of the technology also involves rearrangements of societal structures - what Jasanoff (2004) refers to as the co-production of natural and social order. These processes are particularly 
identifiable through comparison on the level of political units, including nation-states, international organizations and sectorial agencies, where pre-existing institutions and processes for managing nature through policy and regulation influence how technologies are debated and pursued (Ezrahi, 1990; Jasanoff, 2004, 2005; Jasanoff \& Kim, 2009; Mukerji, 1989). This does not mean that such units should be seen as static or deterministic, but rather that their observable influence on technological trajectories offers a productive starting point for analysis of how technologies are interpreted as being in the public interest. Comparing how different political actors define and pursue technological visions can help us understand the range of ways that technological risks, uncertainties and possibilities are understood and acted upon, when and under what conditions they become relevant, and for whom. This in turn provides a basis for understanding public responses and concerns as reactions to changes in the broad range of societal structures that are implicated in and affected by technological change, rather than as isolated reactions to predefined and inherent technological qualities.

The US and the EU are useful units of comparison when it comes to CCS since both have put significant emphasis on the technology in their federal-level approaches to energy and climate change mitigation over the previous decade. New public institutions and private market actors have emerged in response to federal-level developments in both places, influenced in part by the parallel efforts of both the US and the EU to supplement existing state and member state legislation with federal regulation as a way to incentivise private actor investments in the technology. There have been persisting differences in how the prospects of CCS encompassing scepticism as well as support - have been formulated in relation to federal policy priorities, and in how these priorities have been influenced by factors at the level of regions and constituent (member) states. These differences allow us to question the inherency of categorized qualities, possibilities and uncertainties around CCS. Despite their different political formats, the supranational EU and US nation state - the world's largest financial actors - are a frequent topic of comparison on issues of regulatory science and environmental governance (Jasanoff, 2005; Smith, 2012; Vig \& Faure, 2004; Vogel, 2012). While acknowledging their distinctiveness and heterogeneity, I compare the two polities here with a view towards the different ways in which federal-level ambitions have affected pursuits of CCS in two places.

As a yet unrealized object of political support, CCS is funded and debated with reference to what it might become, and beliefs regarding its future role not only reflect isolated assumptions about the technology itself, but also imply expectations about the kind of society it will operate in. Articulations of the purpose of technological pursuits can be read as expressions of sociotechnical imaginaries (Jasanoff \& Kim, 2009), in that they are not simply rationalistic assessments of technical capabilities, but also give insights into how broader societal ambitions affect how technologies are interpreted as political objects. Political narratives, regulatory change and new institutions designed to promote CCS, are understood here as instruments of co-production (Jasanoff, 2004: 39-43), where expectations about how technical artefacts will interact with and support societal structures are stabilized, and publics are implicated or excluded as stakeholders in technological change.

The paper draws on a combination of qualitative, comparative methods, and historical case study approaches. I limit my investigation to the previous decade, which 
has seen political support of CCS intensify in both places (Langhelle \& Meadowcroft, 2009). Data collection took place between October 2011 and October 2012. Building on existing research on the institutional make up of the international CCS community (Stephens et al., 2011; Stephens \& Liu, 2012), I collected official statements, reports, policy recommendations and technology assessments from government and industry bodies, as well as from non-governmental organizations and environmental groups playing prominent roles in the politics and policy of CCS in the two political settings. I also conducted archival research with the Carbon Sequestration Leadership Forum and the Zero Emissions Platform, two institutions whose were founded as part of the federal-level pursuit of CCS by the US and EU respectively. The collection of materials was to some extent informed by informal reviews of media coverage and conversations with professionals from industry, research, government agencies, and environmental organizations at a number of professional meetings and conferences related to the technology. In addition to written sources, I conducted a series of 23 semi-structured interviews ${ }^{1}$ with representatives of several such organizations. Additional perspectives on CCS were collected in the form of reports and position papers from major environmental organizations known to be sceptical of or opposed to the technology, but I refrained from interviewing representatives from these organizations, as my primary focus was on comparing the articulation of official political support in the two contexts.

\section{US: CCS as Economical Pathway to Environmental Protection}

Jasanoff and Kim argue that large-scale technological pursuits allow states to present themselves as responsible regulators and protectors of the public interest (Jasanoff \& Kim, 2009: 121). The language with which then-president George W. Bush announced his Clear Skies and Global Climate Change Initiatives indicates how CCS would be central to US policy justifications both domestically and internationally over the following decade:

[E]conomic growth is key to environmental progress, because it is growth that provides the resources for investment in clean technologies. [My] approach will harness the power of markets, the creativity of entrepreneurs, and draw upon the best scientific research. And it will make possible a new partnership with the developing world to meet our common environmental and economic goals. (White House Office of the Press Secretary, 2002)

"Clean technologies" in this context referred specifically to CCS - a central component in the above policypackages - whose promise of emissions-free fossil fuel power generation would come to support increasingly common US narratives around "clean coal". Bush's climate policies emphasised market mechanisms and technological development as alternatives to government regulation in the form of mandatory cuts in greenhouse gas emissions (Stephens, 2009). The US had funded research on CCS since the 1990s, intensified with the Department of Energy's establishment of a designated Carbon Sequestration Program in 1997 (de Coninck, 2008; Pollak et al., 2011). The early 2000s saw a marked strong and decisive move on the level of national policy towards CCS as a response to linked concerns in the areas of energy production and climate change mitigation. As Stephens notes, energy politics was an important motivator; the US had a historical reliance 
on cheap energy, supplied by imported oil and domestic coal. Maintaining the supply was a political priority, and utilization of domestic coal resources could cure the nation's "addiction" to foreign oil (Stephens, 2009: 25). By deferring to the prospects of market-driven technological development, the US state was thus able to avoid direct interference with industry through regulation, and sidestep the issue of imposing restrictive measures for cutting CO2 emissions.

On the international stage, the US portrayed CCS as an alternative pathway to international cooperation on climate change mitigation. The country had received international criticism for not ratifying the Kyoto Treaty of 1997, which set nationspecific targets for cuts in greenhouse gas emissions. In 2003 the US established the ministerial-level Carbon Sequestration Leadership Forum (CSLF), whose purpose was to promote CCS on the global arena and whose members included governments already pushing for CCS development in their home countries. In 2005 the US led the formation of a second alliance, the AsiaPacific Partnership on Clean Development \& Climate (APP), a partnership of some of the world's highest emitters of $\mathrm{CO} 2$, which presented the development of CCS as one of its most central objectives. The APP's Charter stated that it sought to "complement but not replace the Kyoto Protocol" (APP, 2007). On the US domestic front, however, the US' involvement in these multinational efforts were presented as promoting alternatives to the mandatory emissions cuts prescribed by the Kyoto Protocol:

Rather than making drastic reductions in greenhouse gas emissions that would put millions of Americans out of work and undermine our ability to make long-term investments in clean energy -- as the Kyoto Protocol would have required -- the President's growth-based approach will accelerate the development of new technologies and encourage partnerships on climate change issues with the developing world. (White House Office of the Press Secretary, 2002)

Federal-level US efforts to promote CCS around this time appears to have allowed authorities represent themselves as protectors of the "public interest" both internationally and domestically. Leadership in international collaboration around CCS built alliances around a technology-oriented approach to climate change mitigation that contrasted with the Kyoto Protocol's regulation-based approach. The contrast was emphasized when the Bush administration' presented its role in these alliances to domestic audiences, where greenhouse gas emission reductions were presented as a good insofar as they did not come at the expense of American jobs.

Domestically, US support for CCS appears to be closely linked with questions about regional and local growth. 2003 saw the establishment of a nationwide network on public and private organizations involved in CCS through the Department of Energy's Regional Carbon Sequestration Partnerships, which assessed the potential for CCS deployment in different US regions (US Department of Energy, 2012). Alongside this nationwide mobilization, President Bush announced plans for the CCS demonstration project FutureGen, which would become known as the cornerstone of his administration's climate change program. The US Department of Energy and a consortium of electricity producers and utility companies aimed to build the world's first coal-fired power plant with integrated $\mathrm{CO} 2$ capture and storage. The project site was chosen through a national competition. Selection criteria included a strong emphasis on public support, in a process which attracted national media 
attention as 12 communities from 7 states put in their bids to become the site of a major technological testing-ground. In 2007 the small township of Mattoon, Illinois was selected to host the project. Its citizens had supported the project primarily for the prospects of local job creation, economic development and the prestige of hosting an important technological project (Ashworth et al., 2012; WRI, 2010: 43-45).

Despite initial optimism, the FutureGen project quickly ran into financial challenges and was later redesigned and moved to a different location. Regardless, its emphasis on local support illustrates a broader US trend where CCS developers consider the support from local publics to be an important factor for the fate of individual projects. This is particularly the case in those states where public hearings are an integral part of the project permitting process. In 2009 the Regional Carbon Sequestration Partnerships released best practices for community engagement and encouraged developers to treat local publics as autonomous individuals who were able to formulate their own, independent views about the stakes involved in locating CCS projects near their community. The Partnerships stressed that engagement should focus on identifying local "values and concerns ... as well as the perceived benefits" of CCS projects, and warned that underestimating the importance of public engagement "can contribute to delays, increased costs, and community ill will" (NETL, 2012: 9-14). Similar points were stressed in guidelines on community engagement from the World Resources Institute (WRI, 2010).

Ininterviews, environmentalorganization representatives and policy officials who had helped produce such guidelines indicated that local expectations for CCS appeared to be less connected with its climate change mitigation properties than with the potential of new projects to stimulate local economic growth and job creation. I was also told that local opposition to CCS were often grounded in fears of decreasing property values. One environmental representative stated that their organization had all but given up on establishing support for CCS by referring to its climate change mitigation potential, and that their current strategy foregrounded the economic benefits of the technology. In a separate interview, I was told that an emphasis on the climate change benefits of CCS had actually fostered public opposition in regions of the US where disbelief in anthropocentric climate change was prevalent. In interviews, it appeared that the national level emphasis on CCS as a pathway to economic growth corresponded with a similar focus around individual projects, where local communities displayed particular receptiveness to arguments stressing the economic benefits of CCS projects. Local concerns seemed to both be structured by and reinforcing of framings of CCS as having both environmental and economic consequences, co-producing expectations of technological control of CO2 emissions along with expectations about who would benefit from the new technology.

These responses are not predefined or "natural" responses to the technical qualities of CCS, but instead take shape in relation to factors such as regional scepticism about the existence of climate change. Informants' perceived need to focus on the local economic implications of CCS in public engagement efforts, and to deemphasize the climate change mitigation potential of the technology, thus correspond with the aforementioned political narratives around CCS as an economical as well as an environmental technology. Another important factor here, which is directly comparable to the EU context, can be found in the area of property law. 
Local public stakes in CCS frequently appear to be formulated in relation to US land ownership rights. US developers are obliged to acquire use rights to the geological formations in which $\mathrm{CO} 2$ will be stored. Even though subsurface property rights and the relationship between land ownership and control over water and mineral rights vary significantly among the US states (Wilson \& Gibbons, 2007: 351), the use rights relevant to CO2 storage are generally held by private landowners. As a result, new businesses specializing in navigating regulations and leasing use rights have emerged over the last decade. One such company markets their activity as enabling local land owners to make informed decisions: "we strive to make the landowners - primarily farmers and ranchers - a part of our projects by educating and compensating them for the rights to manage $\mathrm{CO} 2$ in their pore space" (C12 Energy, 2012). Pre-existing legal commitments to the governance of land ownership appears to have not only implicated these citizen-groups as potential economic stakeholders in CCS. It also seems to have stimulated the emergence of a distinct market-driven regime for enrolling citizen stakeholders through the delivery of information, with the implication that autonomous judgement can then be exercised in the face of the new possibilities offered by CO2 storage.

The interpretative flexibility of CCS has allowed unlikely partners to ally in support of the yet undeveloped technology (Pinch \& Bijker, 1984). Pollak and colleagues (2011) have demonstrated that pre-existing economic interests and regulatory regimes for enhanced oil recovery in the US have fostered alliances between environmental organizations and the politically powerful US energy industry. These allies have different ambitions when it comes to policy and regulation. The climate coalition favours policy regimes that encourage geological storage of $\mathrm{CO} 2$ for climate change mitigation, while the energy industry generally pursues CCS on the basis of expectations that regulation of $\mathrm{CO} 2$ emissions is imminent (Pollak et al., 2011). These expectations were strengthened towards the end of President Bush's second term, amid signals of an emerging bipartisan consensus in the US Congress on the need for climate change legislation. In May 2007, a Supreme Court decision found that greenhouse gases could be considered air pollutants, and thus fall under the jurisdiction of the Environmental Protection Agency under the Clean Air Act (Massachusetts v. Environmental Protection Agency, 2007). The landmark decision opened up the possibility of increased regulation of $\mathrm{CO} 2$. Earlier that year, the Global Warming Pollution Reduction Act, which would have increased public funding for research and development of CCS, had been proposed with support from most leading environmental groups (notably including Greenpeace, which in Europe has been among the most outspoken opponents to CCS). However, it did not get past a Senate Committee. Two years later the American Clean Energy and Security Act of 2009, which would have incentivized CCS development by imposing an emissions trading system in the US, was defeated in the Senate.

What environmentalists saw as major legislative setbacks in 2009 reverberated among CCS proponents as well. The weakened prospects for imminent CO2 emission cuts in the US were seen by several informants as having jeopardized the willingness of industry to invest in CCS development, as a result forcing CCS advocates to restate the "business case" for CCS. Several interviewees representing environmental organizations stated that in addition to framing their support for CCS in economic terms they now also deemed it necessary to actively promote 
enhanced oil recovery. Their rationale was that regulatory support for enhanced oil recovery could stimulate industry research and bring down the cost of $\mathrm{CO} 2$ capture. The reorientation of advocacy efforts thus reclassified $\mathrm{CO} 2$ as well, promoting it as a potentially valuable industrial commodity rather than as an environmental hazard in need of containment.

The same trend is visible in a reformulation of government support after 2009. In interviews policy officials described how the US Department of Energy abandoned the label CCS and adopted the abbreviation CCUS, carbon capture, utilization and storage, shifting its focus towards industrial uses of $\mathrm{CO} 2$ as a way of stimulating research on $\mathrm{CO} 2$ capture. On the international stage, internal documents show how the US shifted the focus of the CSLF by instituting a CO2 utilization taskforce and amending the Forum charter to include utilization as a Forum priority (CSLF, 2012: 1-2). In his opening remarks to the 2012 Department of Energy-sponsored annual meeting on CCS, which that year was renamed the Annual Carbon Capture, Utilization and Sequestration Conference, Assistant Secretary of Fossil Energy Chuck McConnell explained the need for a new focus: "We have to look at enhanced oil recovery as a way to make [CO2 storage] happen" (ExchangeMonitor, 2012).

While proposals for market-disruptive greenhouse gas control measures were rejected, then, the view that CCS could offer a pathway to economic growth continued to influence both US discourse and policy on the technology. This has been a recurring theme both in domestic federal level policy discourse and in attempts at influencing international climate change mitigation efforts over the past decade. As the prospects of imminent mandatory domestic cuts in $\mathrm{CO} 2$ emissions became less likely after the failure of new legislation, supporters of CCS have become even more dependent on identifying possible synergies with market-driven industrial uses of $\mathrm{CO} 2$. Alongside these changes, the substance that CCS is designed to control in the first place has straddled different ontological systems within US political narratives, as legal classifications and official agency language has classified $\mathrm{CO} 2$ either as an environmental hazard or as a commodity in search of possible market applications.

\section{EU: CCS as Sustainable Pathway to Europeanization}

As with the US, the EU's engagement with CCS can be read in relation to its relationship with the Kyoto Protocol. However, the EU has attempted to combine support of CCS with a regulation-based approach to climate change mitigation, rather than to pursue the technology as an independent alternative to regulation in its own right. Like the US, the EU as a whole is dependent on imported energy, and its pursuit of CCS over the previous decade is closely linked with its recognition of maintaining energy supplies as a central federal-level concern (Natorsky and Herranz Surralés, 2008). The establishment over the last decade of EUwide regulation of $\mathrm{CO} 2$ emissions, as well as a common market for carbon emission allowances and attempts to promote the interconnection of energy networks, have embedded the pursuit of CCS in broader processes of European integration.

The EU sporadically funded CCS research during the 1990s. However, the technology first appeared on the EU's political agenda in 2005 as the European Commission discussed how the EU could meet the climate change mitigation targets set down in the Kyoto Protocol (which all member countries had transposed into national legislation by 2002) (EC, 2005). The Commission emphasized the need to take advantage of 
synergies between policy areas in order to "[minimize] the cost of abatement policies" (EC, 2005: 3) and recommended CCS as a key priority for EU climate policy. The EU's commitment to the Kyoto Protocol would thus have a strong impact on the ways that CCS became incorporated in visions for a future, sustainable and energy independent Europe.

As Claes and Frisvold (2009) argue, the EU took on a leadership role in international climate change mitigation efforts partly to justify the EU project of integration following its 2004 expansion and the 2005 rejection of attempts to create a consolidated EU constitution. President of the European Commission, José Manuel Barroso had identified the linkages between energy and climate change as an area where the EU could demonstrate decisive and orchestrated action, and the Commission composed a comprehensive Climate and Energy Package. CCS was soon identified as a potential technological bridge between these policy domains. With backing from the European Council, the Commission was charged with establishing a legal framework for CCS and with drafting a policy to support the establishment of up to 12 CCS demonstration projects by 2015 in what was intended to be the EU's flagship CCS programme (European Council, 2007). However, federal-level policies did not necessarily reflect homogenous interests in CCS across the Union. As Fischer (2012: 87-88) points out, EU support of CCS came after significant pressure from the United Kingdom and the Netherlands to make CCS a EU priority, as CCS was met with reluctance from nuclear-dependent France and opposition from Southern European member states where geological characteristics were less suited for geological CO2 storage.

The establishment of CCS as an object of EU-level support did not simply depend on political horse-trading among member states, but also on establishing order among the various industry and civil society forces with stakes in the technology. Following calls for increased integration of European research efforts by the European Council, new institutions called European Technology Platforms (ETPs) had been established as "industry-led stakeholder forums with the aim of defining medium to long-term research and technological objectives and developing roadmaps to achieve them" (EC, 2011). One of the first such platforms was the Zero Emission Fossil Fuel Power Plants Technology Platform ZEP), founded in 2005 to support the growing interest in CCS as a EU-level concern. While the first institutional manifestations of US pursuits of CCS had been on the international stage, one of the first institutional developments to come out of EU federal-level interest in CCS was thus designed to establish a common vision for how the technology could serve a shared, European community. Alongside its formal obligation as research advisor to the European Commission, this platform would soon seek to establish itself as the central EU-level public authority and stakeholder representative on CCS, and its activities are therefore given particular emphasis here.

The platform's membership included equipment suppliers, utility companies and companies in the oil and gas sector, as well as research communities and environmental non-governmental organizations - groups that have often disagreed on the aims and means by which CCS should be pursued in the EU (Claes \& Frisvold, 2009: 224). The ETP framework required these actors to agree on common recommendations to the EC, which would thereby receive joint research advice from a single body. ZEP exemplified the potential of boundary organizations to dually seek representational legitimacy and epistemic authority (Guston, 2001). While research recommendations are fronted 
by industry experts, meeting minutes show ZEP strategically foregrounding its environmental organization members in public communication in an effort to inspire public trust (ZEP, 2007). While the inclusion of environmental organizations was not in itself extraordinary for ETPs, interviewees stated that the Commission had made the unprecedented move of requiring their involvement a condition for ZEP's establishment, as a way of improving the credibility of a platform primarily consisting of members from fossil fuel intensive industries. Nonetheless, the formation of ZEP would set limits on who would get to have the sanctioned attention of the European Commission, as environmental organizations Greenpeace and WWF, both of whom have voiced concerns that funding for CCS might come at the expense of renewable energy technology investments (see especially Greenpeace International, 2008), eventually chose to withdraw rather than being associated with ZEP's positions (ZEP, 2006a:2). The European Commission's legitimation of stakeholders representing the breadth of interests in CCS through ZEP served to dually underwrite the pursuit of the technology as a European venture, and to set limits on who would speak for the technology and its implications. In this respect the platform appears to have functioned as a deliberative forum for European industry experts in a process which also set limits on civic representation and justified "the inclusion or exclusion of citizens with respect to the benefits of technological progress" (Jasanoff \& Kim, 2009: 120).

In 2006, ZEP released its first set of research recommendations along with a "Vision Paper" outlining plans for emissionsfree power plants by 2020 , facilitated by EUinvestments in CCS - a target which the then Commissioner for Science and Research Janez Potocnik stated would both stimulate and benefit from European integration (ZEP, 2006b: 7). ZEP presented deployment of CCS as a necessary response to the need to maintain the EU's energy supply after the EU enlargement of 2004, and argued that reliance on fossil fuels for energy generation was inevitable in anticipation of a transition to a "fully sustainable energy economy' (ZEP, 2006b: 11-15).

While founded as a research advisor to the EC, ZEP soon sought to establish itself as a public authority on CCS as well. However, the platform adopted a different strategy to public engagement than the dialogue-focused approach that had characterized CCS advocacy in the US. Taking a decidedly deficit model view of the dynamics of public engagement with technology, ZEP approached its audiences as passive recipients of information (Irwin \& Wynne, 1996), and aligned itself with an often criticized tradition in EU bureaucracy of legitimizing technology with deference to expert judgments rather than civic deliberation (Felt et al., 2007; Hagendijk \& Irwin, 2006; Sundqvist \& Elam, 2010). Assumption about the public as consisting of a homogeneous pan-European audience is reflected in information materials that ZEP distributes across EU member countries, which presents the technology as both essential and as safe and predictable when governed by EU legislation (ZEP, 2009: 25). The emphasis appears to be on presenting technical facts about the safety of the technology and its ability to address EU-level environmental and energy policy goals, rather than on addressing the diverse implications CCS might have for different groups of publics in the EU.

In line with recommendations from ZEP, EU's support mechanisms for CCS would eventually make public funding for the technology inseparable from broader aims of European integration. In 2005 the Union launched its Emissions Trading System - 
the world's first market for greenhouse gas emission allowances, and similar to the regime which US legislators would come to reject in 2009. The system caps emissions based on the EU's climate change targets, and allowances are traded on an internal European market. The main EU financing instrument for CCS - NER300, which would stimulate the development of the aforementionedflagshipCCSdemonstration programme - sought to subsidize CCS development through the sale of 300 million CO2 emission allowances, thus making EU-level support of CCS dependent on the success of the Union's carbon market. And following the 2008 global financial crisis, the establishment of the EU's European Energy Programme for Recovery explicitly sought to allocate project support according to principles of European integration, and to take geographic distribution of funds across the Union, as well as distribution of funds between old and new member countries, into account alongside the evaluation of the technical merit of potential CCS projects.

As described above, the failure of US climate change legislation had led CCS proponents in environmental organizations and federal agencies to reformulate their narratives around $\mathrm{CO} 2$, representing it as a potentially valuable industrial commodity, rather than as a waste to be disposed of. Within the EU, the pursuit of CCS has led to parallel changes in the classification of $\mathrm{CO} 2$, but within legal ontologies rather than in policy narratives. The EU's commitment to international treaties for the protection of marine environments posed potential legal barriers to CO2 storage efforts (de Coninck et al., 2007: 410). For instance, the 1992 OSPAR Convention on the Protection of the Marine Environment of the North-East Atlantic prohibited polluting activities in the sub-seabed and subsoil. The Convention was amended in 2007 so as to allow subseabed storage of $\mathrm{CO} 2$, and to rule out the definition of $\mathrm{CO} 2$ as "waste" under the convention (Purdy \& Havercroft, 2007). In legal terms, the position of $\mathrm{CO} 2$ was shifted from unwanted waste to "non-waste" as part of broader efforts to promote CCS.

While the active facilitation of public engagement with CCS has been a priority for technology developers in the US, a lack of dialogue and trust between developers and communities has characterized highprofile controversies around CCS in EU member states - most famously in the Dutch town of Barendrecht (Feenstra et al., 2010). In the comparative context of this article, one possible factor to consider here is how the aforementioned enrolment of private land owners as economic stakeholders in US CCS projects, is generally absent under European property regimes. In the EU, it is generally nation states rather than private landowners who control potential CO2 storage sites (Wilson \& Gibbons, 2007: 351). Where US law had stimulated new business models that offered potential economic benefits to farmers and other landholders, some of the economic incentives that seem to have influenced community support for CCS projects in the US are absent within the EU. It seems plausible that this contrast has broader implications for the degree to which EU CCS advocates and developers consider it necessary to support public engagement efforts in order to build support for the technology - something which might in turn illuminate the contrast between ZEP's approach to public communication and that of its US counterparts.

\section{Conclusions: Structuring Visions}

This article has sought to identify distinctive features of the engagement with CCS in the US and EU over the previous decade. I have looked at how political pursuits of CCS have taken form in relation to different political commitments and priorities, and given rise 
to new institutions and legal frameworks. These factors show important differences between the two sites in terms of how CCS has become presented as a public good, and in terms of how different publics have become implicated as stakeholders in the technology. My approach has sought to complement existing strands of research on the public perceptions and political motivations around CCS, by examining "instruments for the co-production of natural and social order" (Jasanoff, 2004: 39-43) in the form of political narratives, regulatory frameworks and institutional formations and practices. The paper has taken an exploratory approach to unpack some of the "stakes behind the policies" of federal-level pursuits of emerging technologies, rather than to attempt to provide an exhaustive account of policy developments (Jasanoff \& Kim, 2009: 139). It has also sought to explore possible links between market and governance structures on one hand and the enrolment of publics as stakeholders on the other, rather than to take public attitudes to CCS as given or predefined in relation to abstract notions of what constitutes the risks and possibilities of the technology. Notably, legal ontological shifts have been illustrative in terms of signalling broader visions for CCS, as both political actors have reclassified $\mathrm{CO} 2$ in order to justify the pursuit of CCS, rendering the substance governable either as property, waste, hazard or commodity, or sanitized "non-waste".

In the US, CCS has been pursued as an alternative to the Kyoto Protocol's regulatory approach to greenhouse gas control, and presented as a technological measure more compatible with economic growth. Early institutional manifestations of this pursuit included multinational alliances initiated around CCS, which displayed US climate change efforts to an international audience, while the technology was presented as protecting American jobs to domestic audiences. The interpretative flexibility of CCS has thus supported political narratives that acknowledge the need to act on climate change, while at the same time abstaining from imposing regulation on the private sector, or interfering with the supply of cheap energy to its citizens. The emphasis on economic growth extended to the level of individual CCS projects as well, and local publics have been cast in the role of legitimate stakeholders motivated by interests in the benefits projects might bring to their communities.

In the EU, CCS has been presented as a technology reconciling climate change mitigation commitments and energy needs, and put to the service of European integration. Political support for the technology has taken shape in coordination with the world's first major CO2 emissions trading scheme, which is internal to the EU and closely linked with aims of European integration. On the level of individual CCS projects, state ownership of underground space has cast local publics in a more passive role than in the US, and social mobilization around the technology has centred more on questions about local health and safety concerns, than on the potential for local economic growth. By facilitating the establishment of a single institution, a coalition of actors under the heading of a European Technology Platform, the European Commission ensured that CCS advocates would be required to present joint visions and recommendation for the technology, despite internal differences, if they were to have a formal and privileged position as a stakeholder forum. Some CCS-sceptical environmental organizations found it necessary to withdraw from the platform, even as this meant giving up the chance to influence European research priorities through a formalized process. Nevertheless, the continued participation of other environmental organizations as members 
alongside industry representatives allowed the platform to lay claim to representational legitimacy alongside its epistemic authority on matters of technology development.

In the US, land tenure appears to have been a "powerful [instrument] of meaningmaking" (Jasanoff \& Kim, 2009: 123124). Here, subsurface rights facilitated the enrolment of private landowners as economic stakeholders in CCS, as they stood to benefit from the increasing value of lands suitable for $\mathrm{CO} 2$ storage. Along with these economic incentives, however, came a need for landowners to formulate and act on autonomous judgements about the stakes involved. This involved weighing questions about the potential risks and uncertainties about CO2 storage - the source of highprofile controversies around CCS in the EU - against the potential for profit. Community engagement as practiced by companies like C12 Energy and by CCS advocates and project developers, thus served to provide publics with an epistemic basis on which to exercise presumed autonomy. In the EU, by contrast, member state control of the relevant subsurface use rights removed some of the economic incentives that had contributed to local support for CCS in the US. A tradition of expert authority operating with a conception of publics as passive recipients of science and technology, and the need for CCS proponents to respond to public controversies and fears about the safety of geological storage, appears to have fostered communication efforts more concerned with sanitizing CCS, than with facilitating civic deliberation on it.

Since the focus here has been on identifying possible links between patterns of public engagement and the various legislative mechanisms that affect the stakes of different groups of publics in the development of CCS projects, it has been outside the scope of this article to assess whether the contrasting communication activities can be said to be "successful" in their respective contexts. However, further research on legal and other mechanisms affecting public responses to emerging technologies could be an important supplement to attitude surveys and focus group research.

Delegation of agency to the private sector and deferrals to technological promise as a substitute for government control, has characterized the pursuit of CCS in the US. Even after the failure of policy measures designed to curb greenhouse gas emissions, CCS has continued to be portrayed as both environmentally responsible and consistent with economic growth, as support for the technology has become increasingly centred on the prospects for industrial utilization of $\mathrm{CO} 2$. Those who see enhanced oil recovery as either an end in itself, or as a stepping-stone for technology development facilitating CCS for climate change mitigation purposes, currently collaborate in the pursuit of industrial utilization of $\mathrm{CO} 2$. However, deep-seated differences between what different groups see as the ultimate purpose of CCS in the US raises serious doubts about the permanence of their alliance. In the EU the choice of linking state financial incentives for development of CCS to the EU's system for trading greenhouse gas quotas, made the fate of the technology inseparable from the success of the panEuropean market for carbon allowances. The recent and dramatic devaluation of such allowances (Mahony, 2012) has reduced the incentives for industry to develop CCS.

In both political settings, CCS has been pursued in accordance with distinct political and regulatory norms, and commitments to different visions of the role of federal actors in protecting public interests. By examining how such features are built into publicly supported technological projects, we can hope to improve our understanding of how mobilization around universalized 
conceptions of science and technology become situated within political contexts. While climate change mitigation currently appears to depend on international cooperation founded on a shared epistemic basis, it is important that mitigation options are not simply assessed as mere functions of economic projections, but that attention is also paid to assumptions about the societal implications of envisaged technological projects, and the potential disparity in how political actors formulate and pursue them.

\section{Notes}

1 Interviewees included representatives from the US Department of Energy, the Carbon Sequestration Leadership Forum, the Natural Resources Defence Council, World Resources Institute, the European Commission, the Zero Emission Fossil Fuel Power Plants Technology Platform, the Bellona Foundation, the World Bank and the International Energy Agency. Echoing the approach of Dryzek and colleagues (2003), interviews were used as a way of pursuing theory-driven questions that were not necessarily addressed or elaborated on in official documents. Thus, informants were asked about the broader social, political and legal contexts that influenced the form and content of public support mechanisms for CCS in the US and EU, and how these conditions affected the work of their respective organizations. They were also asked about how they perceived other actors' motives, or perspectives towards CCS that contrasted with their own. The professional CCS community is relatively small (one informant referred to international CCS conferences as "family reunions"), and individuals often hold professional roles in several organizations concurrently. In order to encourage openness in interviews, the anonymity of informants is protected by referencing publicly available written sources whenever possible, and by restricting details about interviewee affiliations. However, the explorative nature of the study makes it relevant to also include certain personal anecdotes and claims in the text.

\section{Acknowledgements}

I am grateful for valuable comments on this paper from Professor Göran Sundqvist and Professor Sheila Jasanoff, as well as from the team of editors and three anonymous reviewers. This work was carried out during a Visiting Fellowship at the Program on Science, Technology \& Society at Harvard University's Kennedy School of Government. It has been supported by grants from the Research Council of Norway (project 209247/V11), the Ryoichi Sasakawa Young Leaders Fellowship Fund, Legatet "Patrick Geddes-samlingen", Ella og Robert Wenzins legat ved Universitetet i Oslo, Jansons legat, as well as the Norway-America Association's Ragnhild Marianne Løkens Education Fund and King Olav V Stipend.

\section{References}

Anderson, J. \& J. Chiavari (2009) 'Understanding and improving NGO position on CCS, Energy Procedia 1: 4811-17.

APP (2007) 'Asia-Pacific Partnership on Clean Development and Climate Charter', http://www.asiapacificpartnership.org/ pdf/resources/charter.pdf.

Ashworth, P., J. Bradbury, S. Wade, C. F. J. Ynke Feenstra, S. Greenberg, G. Hund \& T. Mikunda (2012) 'What's in store: Lessons from implementing CCS', International Journal of Greenhouse Gas Control 9: 402-9.

Associated Press (2007) "Low-carbon economy' proposed for Europe', http:// www.msnbc.msn.com/id/16560106/ns/ 
world_news-world_environment/t/lowcarbon-economy-proposed-europe/.

Bijker, W. E., T. P. Hughes \& T. J. Pinch (eds) (1987) The Social Construction of Technological Systems: New Directions in the Sociology and History of Technology (Cambridge: MIT Press).

Bäckstrand, K., J. Meadowcroft \& M. Oppenheimer (2011) 'The politics and policy of carbon capture and storage: Framing an emergent technology, Global Environmental Change 21(2): 275-81.

C12 Energy (2012) 'We manage industrial CO2 in the most profitable way', http:// c12energy.com/about-co2-storage/.

Claes, D. H. \& P. Frisvold (2009) 'CCS and the European Union: magic bullet or pure magic?' in J. Meadowcroft \& O. Langhelle (eds), Caching the Carbon: The Politics and Policy of Carbon Capture and Storage (Cheltenham, UK: Edward Elgar Publishing): 211-35.

CSLF (2012) 'MEETING SUMMARY CO2 Utilization Options Task Force Meeting Bergen, Norway 11 June 2012', http:// www.cslforum.org/publications/ documents/bergen2012/SummaryCO 2UtilizationOptionsTaskForceMeetingBergen0612.pdf.

de Coninck, H. (2008) 'The international race for $\mathrm{CO} 2$ capture and storage: And the winner is...?', FACET Commentary (12).

de Coninck, H., J. Anderson, P. Curnow, T. Flach, H. Groenenberg, C. Norton, D. Reiner, S. Shackley \& G. Sigurthorsson (2007) 'Is CO2 capture and storage ready to roll?', Journal for European Environmental \& Planning Law 4(5): 402-14.

de Coninck, H., \& K. Bäckstrand (2011) 'An International Relations perspective on the global politics of carbon dioxide capture and storage,' Global Environmental Change 21(2): 368-78.
Dryzek, J., D. Downes, C. Hunold, D. Schlosberg \& H-K. Hernes (2003) Green States and Social Movements: Environmentalism in the United States, United Kingdom, Germany, and Norway (Oxford: Oxford University Press).

EC (2005) Winning the Battle Against Global Climate Change. Brussels 9.2.2005 COM (2005) 35 final.

EC (2011) 'About ETPs', http://cordis. europa.eu/technology-platforms/about_ en.html.

European Council (2007) European Council 8/9 March 2007 Presidency Conclusions. Brussels 2.5.2007 7224/1/07.

ExchangeMonitor. (2012) '11TH ANNUAL CCUS CONFERENCE ATTRACTS NEARLY 600', http://www.carbonsq. com/pdf/2012/2012_overview.pdf.

Ezrahi, Y. (1990) The Descent of Icarus: Science and the Transformation of Contemporary Democracy (Cambridge: Harvard University Press).

Vig, N.J. \& M.G. Faure (2004) Green Giants? Environmental Policies of the United States and the European Union (Cambridge: MIT Press).

Feenstra, C.F.J., T. Mikunda \& S. Brunsting (2010) 'What happened in Barendrecht? Case study on the planned onshore carbon dioxide storage in Barendrecht, the Netherlands' (Petten, Netherlands: ECN and Global CCS Institute).

Felt, U., B. Wynne, M. Callon, M. Gonçalves, S. Jasanoff, M., Jepsen, P.-B., Joly, Z. Konopasek, S. May, C. Neubauer, A. Rip, K. Siune, A. Stirling \& M. Tallacchini. (2007) 'Taking European Knowledge Society Seriously. Report of the Expert Group on Science and Governance to the Science, Economy and Society Directorate, Directorate General for Research, European Commission', http:// ec.europa.eu/research/science-society/ document_library/pdf_06/europeanknowledge-society_en.pdf. 
Fischer, S. (2012) 'Carbon Capture and Storage: The Europeanization of a Technology in Europe's Energy Policy?' in F. Morata \& I. S. Sandoval (eds), European Energy Policy: An Environmental Approach (Cheltenham: Edward Elgar Publishing): 85-96.

Global CCS Institute (2012) The Global Status of CCS: 2012 (Canberra: Global CCS Institute).

Guston, D. H. (2001) 'Boundary Organizations in Environmental Policy and Science: An Introduction', Science, Technology \& Human Values 26(4): 399408.

Greenpeace International (2008) False Hope: Why Carbon Capture and Storage Won't Save the Climate (Amsterdam: Greenpeace International).

Hagendijk, R. \& A. Irwin (2006) 'Public Deliberation and Governance: Engaging with Science and Technology in Contemporary Europe', Minerva 44(2): 167-84.

Hennink, M, I. Hutter \& A. Bailey (2011) Qualitative Research Methods (London: Sage).

Huijts, N.M.A., C.J.H. Midden \& A. L. Meijnders (2007) 'Social acceptance of carbon dioxide storage', Energy Policy 35(5): 2780-9.

IEA (2009) Technology Roadmap: Carbon capture and storage (Paris: IEA).

IPCC (2005) IPCC Special Report on Carbon Dioxide Capture and Storage (New York: Intergovernmental Panel on Climate Change).

Irwin, A., \& B. Wynne. (1996) Misunderstanding Science?: The Public Reconstruction of Science and Technology (Cambridge, UK: Cambridge University Press).

Jasanoff, S. (ed) (2004) States of Knowledge : The Co-production of Science and Social Order (London: Routledge).
Jasanoff, S. (2005) Designs on nature: science and democracy in Europe and the United States (Princeton: Princeton University Press).

Jasanoff, S., \& S.-H. Kim (2009) 'Containing the Atom: Sociotechnical Imaginaries and Nuclear Power in the United States and South Korea', Minerva 47(2): 119-46.

Langhelle, O., \& J. Meadowcroft, J. (2009) 'CCS in comparative perspective' in O. Langhelle \& J. Meadowcroft (eds), Caching the Carbon: The Politics and Policy of Carbon Capture and Storage (Cheltenham, UK: Edward Elgar Publishing): 236-266.

Mahony, H. (2012) 'Brussels moves to tackle slumped carbon market', http:// euobserver.com/economic/117066.

Markusson, N., F. Kern \& J. Watson (2011) 'Assessing CCS viability - A sociotechnical framework', Energy Procedia 4: 5744-51.

Markusson, N., S. Shackley \& B. Evar (eds) (2012) The Social Dynamics of Carbon Capture and Storage: Understanding CCS Representations, Governance and Innovation (New York: Routledge).

Massachusetts v. Environmental Protection Agency 549 U.S. 497 (2007).

Meadowcroft, J. \& O. Langhelle (eds) (2009) Caching the Carbon: The Politics and Policy of Carbon Capture and Storage (Cheltenham, UK: Edward Elgar Publishing).

MIT (2007) The Future of Coal: Options for a Carbon Constrained World. (Cambridge: MIT).

Mukerji, C. (1989) A Fragile Power: Scientists and the State (Princeton: Princeton University Press).

Narita, D. (2010) 'Managing uncertainties: The making of the IPCC's Special Report on Carbon Dioxide Capture and Storage', Public Understanding of Science 21(1): 84-100. 
Natorsky, M. and A. Herranz Surralés (2008) 'Securitizing Moves To Nowhere? The Framing of the European Union's Energy Policy,' Journal of Contemporary European Research 4(2): 71-89.

NETL. (2012) 'Carbon Storage FAQ Information Portal: Permanence and Safety of CCS,' http://www.netl.doe. gov/technologies/carbon_seq/FAQs/ permanence $2 . h$ tml

Nykvist, B. (2013) 'Ten times more difficult: Quantifying the carbon capture and storage challenge,' Energy Policy 55: 6839.

Oltra, C., R. Sala, R. D. Solà, M. Di Masso, \& G. Rowe (2010) 'Lay perceptions of carbon capture and storage technology', International Journal of Greenhouse Gas Control 4(4): 698-706.

Pacala, S., \& R. Socolow (2004) 'Stabilization Wedges: Solving the Climate Problem for the Next 50 Years with Current Technologies', Science 305(5686): 968972.

Pinch, T. J. \& W. E. Bijker (1984) 'The Social Construction of Facts and Artefacts: or How the Sociology of Science and the Sociology of Technology might Benefit Each Other,' Social Studies of Science 14(3): 399-441.

Pollak, M., S. J. Phillips \& S. Vajjhala (2011) 'Carbon capture and storage policy in the United States: A new coalition endeavors to change existing policy,' Global Environmental Change 21(2): 313-23.

Purdy, R. \& I. Havercroft (2007) 'Carbon Capture and Storage: Developments under European Union and International Law', Journal for European Environmental \& Planning Law 4(5): 353-66.

Rubin, E. S., H. Mantripragada, A. Marks, P. Versteeg \& J. Kitchin. (2012) 'The outlook for improved carbon capture technology', Progress in Energy and Combustion Science 38(5): 630-71.
Shackley, S. (2012) 'Introduction to Part II: Governance', in N. Markusson, S. Shackley \& B. Evar (eds), The Social Dynamics of Carbon Capture and Storage: Understanding CCS Representations, Governance and Innovation (New York: Routledge): 111-26.

Shackley, S \& B. Evar (2012) 'Up and down with CCS: The issue-attention cycle and the political dynamics of decarbonisation', in N. Markusson, S. Shackley \& B. Evar (eds), The Social Dynamics of Carbon Capture and Storage: Understanding CCS Representations, Governance and Innovation (New York: Routledge): 14987.

Singleton, G., H. Herzog, \& S. Ansolabehere (2009) 'Public risk perspectives on the geologic storage of carbon dioxide,' International Journal of Greenhouse Gas Control 3(1): 100-7.

Smith, M.P. (2012) Environmental and Health Regulation in the United States and the European Union: Protecting Public and Planet (New York: Palgrave Macmillian).

Stigson, P., A. Hansson, \& M. Lind (2012) 'Obstacles for CCS deployment: An analysis of discrepancies of perceptions', Mitigation and Adaptation Strategies for Global Change 17(6): 601-19.

Stephens, J. C. (2009) 'Technology leader, policy laggard: CCS development for climate mitigation in the US political context', in O. Langhelle \& J. Meadowcroft (eds), Caching the Carbon: The Politics and Policy of Carbon Capture and Storage (Cheltenham, UK: Edward Elgar Publishing): 22-49.

Stephens, J. C., A. Hansson, Y. Liu, H. de Coninck \& S. Vajjhala (2011) 'Characterizing the international carbon capture and storage community', Global Environmental Change 21(2): 379-90. 
Stephens, J. C., \& Y. Liu (2012) 'The evolving international CCS community' in N. Markusson, S. Shackley \& B. Evar (eds), The Social Dynamics of Carbon Capture and Storage: Understanding CCS Representations, Governance and Innovation (New York: Routledge): 12748.

Sundqvist, G., \& M. Elam (2010) 'Public Involvement Designed to Circumvent Public Concern? The 'Participatory Turn' in European Nuclear Activities', Risk, Hazards \& Crisis in Public Policy 1(4): 203-29.

Stern, N. (2007) The Economics of Climate Change: The Stern Review (Cambridge: Cambridge University Press).

The Economist (2012) 'Shale gas: Fracking great', http://www.economist.com/ node/21556249.

Tjernshaugen, A. (2008) 'Political commitment to $\mathrm{CO} 2$ capture and storage: evidence from government RD\&D budgets,' Mitigation and Adaptation Strategies for Global Change 13(1): 1-21.

Upham, P., \& T. Roberts (2011) 'Public perceptions of CCS: Emergent themes in pan-European focus groups and implications for communications,' International Journal of Greenhouse Gas Control 5(5): 1359-67.

US Department of Energy (2012) 'Carbon Storage: Regional Carbon Sequestration Partnerships', http://www.netl.doe. gov/technologies / carbon_seq/ infrastructure/rcsp.html.

Vogel, D. (2012) The Politics of Precaution: Regulating Health, Safety, and Environmental Risks in Europe and the United States (Princeton: Princeton University Press).

White House Office of the Press Secretary (2002) 'Fact Sheet: President Bush Announces Clear Skies \& Global Climate Change Initiatives', http://georgewbushwhitehouse.archives.gov/news / releases/2002/02/20020214.html
Wilson, E. J., \& A. J. Gibbons (2007) 'Deploying Carbon Capture and Storage in Europe and the United States: A Comparative Analysis,' Journal for European Environmental \& Planning Law 4(5): 343-52.

Winner, L. (1988) The Whale and the Reactor: A Search for Limits in an Age of High Technology (Chicago: University of Chicago Press).

Wynne, B. (1988) 'Unruly Technology: Practical Rules, Impractical Discourses and Public Understanding, Social Studies of Science 18(1): 147-67.

WRI (2010) Guidelines for Community Engagement in Carbon Dioxide Capture, Transport, and Storage Projects (Washington DC: WRI).

Yin, R. K. (2009) Case Study Research: Design and Methods (London: Sage).

ZEP (2006a) ZEP Communication Working Group Minutes - 18 December 2006 (Brussels: Zero Emission Fossil Fuel Power Plants Technology Platform).

ZEP (2006b) A Vision for Zero Emission Fossil Fuel Power Plants (Brussels: Zero Emission Fossil Fuel Power Plants Technology Platform).

ZEP (2007) Notes of Public Communication Taskforce meeting \#4, 4th September 2007 (Madrid: Zero Emission Fossil Fuel Power Plants Technology Platform).

ZEP (2009) Capturing and storing CO2: The hard facts behind CCS (Brussels: Zero Emission Fossil Fuel Power Plants Technology Platform).

Mads Dahl Gjefsen

TIK - Centre for Technology, Innovation and Culture

University of Oslo

Pb. 1108 Blindern

0317 Oslo, Norway

madsdg@cantab.net 